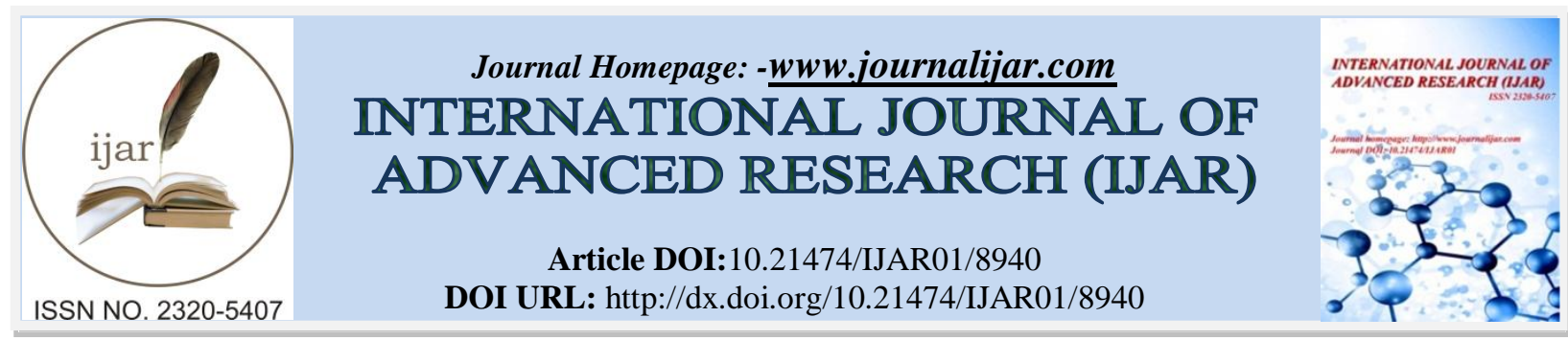

RESEARCH ARTICLE

\title{
EFFECTS OF SEMI-ABLATIVE FRACTIONAL RADIOFREQUENCY IN DERMAL TISSUE.
}

\section{Rodrigo Marcel Valentim da Silva ${ }^{1}$, Nattállia Carollina Cordeiro de Andrade ${ }^{2}$, Thâmara Raquel Santos de Oliveira $^{2}$, Liliane Santos de Vasconcellos ${ }^{3}$, Patrícia Froes Meyer ${ }^{4}$, Yuri Alexander Afonso ${ }^{4}$, Ciro Dantas Soares $^{5}$, Silene Bazi Ribeiro ${ }^{6}$, Thayná Melo de Lima Morais ${ }^{7}$, Júlio Davi Costa e Silva ${ }^{8}$, Fábio dos Santos Borges $^{8}$, Eneida de Morais Carreiro'.}

1. PhD in Physical Therapy, Federal University of Rio Grande do Norte - UFRN. Professor of the Physiotherapy course of Faculdade Estácio Ponta Negra, Natal / RN and Faculdade Uninassau, Natal / RN.

2. Physiotherapist graduated from Potiguar University - UnP.

3. MSc in Physiotherapy in progress with the Federal University of Rio Grande do Norte - UFRN.

4. $\mathrm{PhD}$ in Health Sciences. Professor at Potiguar University - UnP.

5. PhD student, Stomathopathology; MSc in Stomathopathology - State University of Campinas (UNICAMP), São Paulo/SP, Brazil.

6. Bachelor of Physiotherapy from Feevale University, Specialist in physiotherapy dermato funcional by CBES, Master's degree in physiotherapy from Universidade Fernando Pessoa - Portugal.

7. PhD student, Stomathopathology; MSc in Stomathopathology - State University of Campinas (UNICAMP), São Paulo/SP, Brazil.

8. Physiotherapist, MSc in Pedagogical Sciences.

9. Master in Biotechnology. Researcher at the International Research Group.

\section{Manuscript Info}

\section{Manuscript History}

Received: 22 February 2019

Final Accepted: 24 March 2019

Published: April 2019

Key words:-

Physiotherapy. Fractional

Radiofrequency. Rejuvenation.

\section{Abstract}

The use of radiofrequency serves the purpose of improving dermal aging through new collagen fibres formation, making the skin firmer. The objective of this study is to investigate the effects of fractional radiofrequency on the dermal tissue of the palpebral region in women. The research was carried out with 10 volunteers of mean age $53.5 \pm$ 4.95 years, who presented upper palpebral skin sagging. The patients underwent four sessions, one every fifteen days. The procedure was performed with the volunteers in dorsal decubitus, using the fractional radiofrequency equipment with $20 \mathrm{~mJ}$ of energy, and electrodes of 8 or 25 -needle tips during ten minutes. The assessments required for treatment were performed at all sessions and fifteen days after the last session for results comparison. In the histological analysis, only one volunteer was submitted to blepharoplasty, in which two samples of the skin flap of the upper palpebral region were removed. The results were positive, both in clinical and histological analyses, even though smaller semiablative doses were used. The results showed a significant improvement in the whole region, showing greater presence of collagen, as well as of inflammatory cells, confirming that the treatment using fractional radiofrequency for skin flaccidity has its effectiveness at clinical and histological levels.

Copy Right, IJAR, 2019,. All rights reserved. 


\section{Introduction:-}

There are several treatment alternatives for skin appearance improvement with consequent flaccidity reduction . One of them is the conventional radiofrequency; a device developed to act in the dermatological area. It is a technology used with the purpose of improving dermal aging effects through the formation of new collagen fibres, promoting skin firmness. It acts on the deep layer of skin, modelling collagen fibrils and softening sagging effects. This skin reconditioning improves its modulation, making it more elastic, promoting better interaction between tensile forces of the tissues, now composed of better fibre collagen, causing improvement of both corporal and facial flaccidity (Carvalho et al., 2011).

Fractional radiofrequency uses the thermal production from the tissues impedance and, as a consequence, the heat diffusion reaches the deeper tissues. An advantage of the fractional radiofrequency system is that it causes less epidermal breakdown (Tierney et al., 2012; Hruza et al., 2009).

The conventional radiofrequency is a non-ablative procedure, but the fractional model can be considered ablative, depending on the applied power and on the tissue response to the procedure. Both have reported effectiveness in skin rejuvenation, but the fractional radiofrequency is able to microscopically induce thermally coagulated columns of dermal tissue into skin surface spaced matrices, leading to its regulation and to new collagen production, leaving parts of the tissue intact and resulting in faster improvement of the treated region. In radiofrequency, the tip type used during the procedure determines the concentration of energy at a point; then, the smaller the contact area (electrode tip), the greater the ablation or evaporation power. There are three types of emitters: standard, textured, and with needles (Casabona et al., 2014, Akita et al., 2014, Huang et al., 2018, Chrastil et al., 2008, Fitzpatrick et al., 2003, Vejjabhinanta et al., 2018).

The study of Kolodziejczak and Rotsjztejn (2018), who used the conventional radiofrequency around the eyes to reduce the signs of aging, followed the protocol of laser $1.410 \mathrm{~nm}$ with two-week intervals between sessions. Alexiades-Armenakas (2010) showed superior effects of fractional radiofrequency when compared to conventional radiofrequency and its advantages over invasive procedures. Casabona et al. (2014) presented 20 cases with safe and positive results for the eyelid region after the application of ablative fractional radiofrequency with the assistance of previous local infiltrative anaesthesia.

In view of the above, this study aims to investigate the effects of lower doses (semi-ablative) fractional radiofrequency on the dermal tissue in the eyelid region in women used with no previous anaesthesia.

\section{Resources and procedures}

Research characterization/study type

This was a randomized blind study, characterized as a clinical trial.

\section{Population And Sample}

The study was carried out in the city of Natal/RN, Brazil, from April to July 2018 with 10 female volunteers. The research had two subgroups to which the volunteers were randomly assigned: G1 with five volunteers (tip with 25 needles), and G2 with another five volunteers (tip with 8 needles), as shown in Fig. 1. 


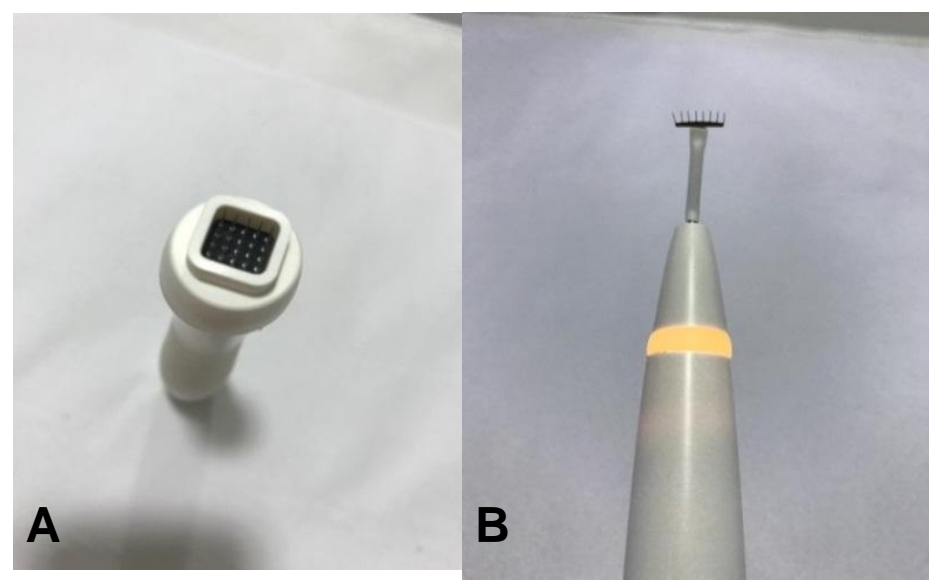

Figure 1. Presentation of disposable electrodes and accessories included in the Fractional Radiofrequency equipment.

\section{Instruments}

The instruments used were the following: paper sheets; procedure gloves; a dermatographic pencil; a pachymeter (Nove54); a mobile phone for photo registration (Moto G5S, Motorola); a fractional radiofrequency equipment (Tone Derm, model ARTIS, Brasil; miscellaneous surgical material: scalpel, absorbable suture yarn (Vicryl 3-0); material for analysis such as photos of volunteers; skin flap samples, photogrammetry, and questionnaires, which were the Narese Global Aesthetic Improvement Scale (GAIS) questionnaire and the one created by Segot-Chicq et al. (2007), whose adapted version was used. Based on these questionnaires, a third one was developed for comparative skin appearance evaluation before and after the use of fractional radiofrequency on the eyelid skin.

\section{Procedures}

The volunteers were guided regarding the procedures to be performed and signed the Informed Consent Term (TCLE). The volunteers received application in the palpebral region according to their groups: Group 1 (G1) received 4 applications on eyelid (25-needle tip) each person; and Group 2 (G2) received 4 applications on eyelid (8-needle tip) each person.

For all volunteers, regardless of group, the evaluation started as follows: frontal and lateral view photos were taken with the volunteers in a sedestation position, with the back of the wall as support to ensure posture, on a $40 \mathrm{~cm}$-high seat. A mobile phone Motorola G7 was used for photo taking; the same was used in all photos, positioned $103 \mathrm{~cm}$ from the floor, $18 \mathrm{~cm}$ away from the volunteer. The measurements were performed after the photographic records, before and after the procedure, with a pachymeter, an equipment that aims to precisely measure small distances. The measures were determined by the distance between eyebrows, eyebrow size, highest point, initial height, highest point height, and final point height (Fig. 2). 

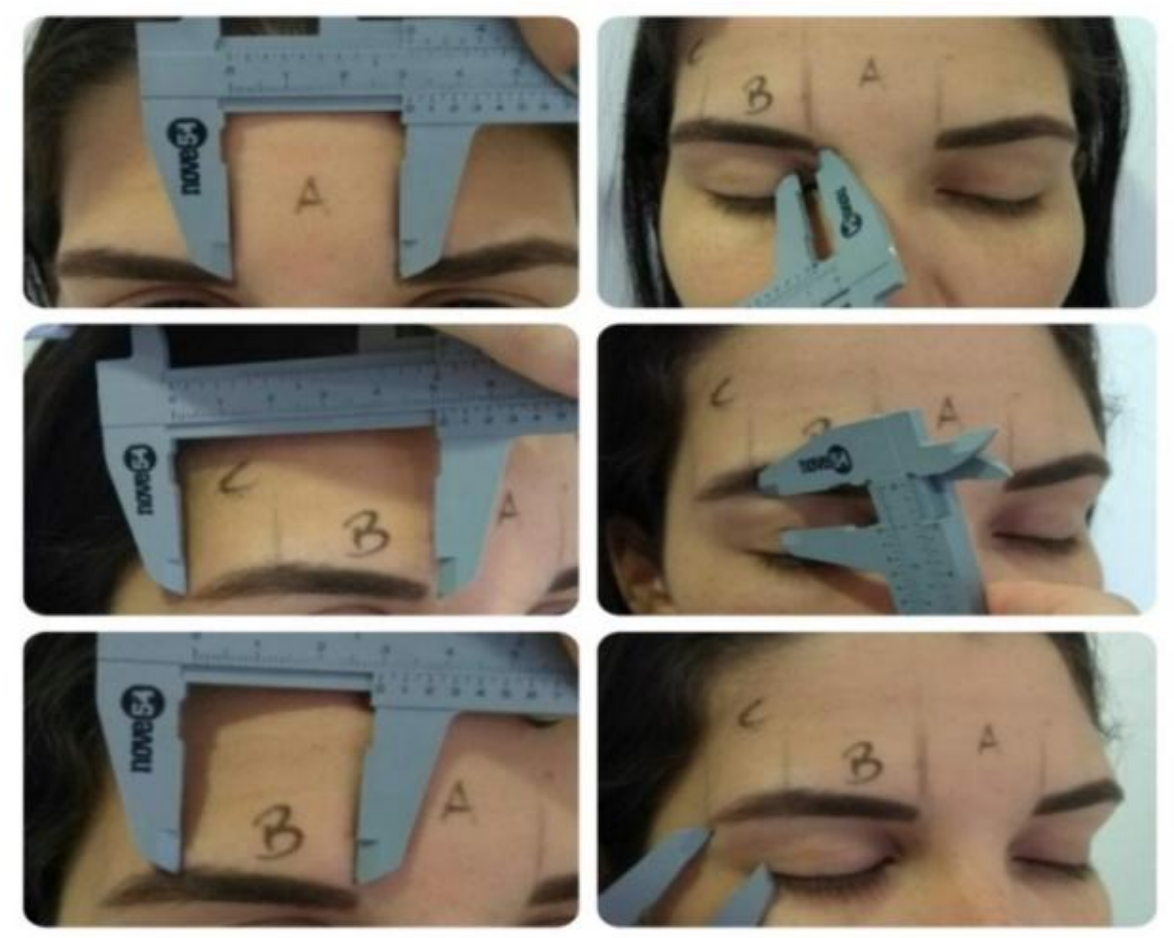

Figure 2. Presentation of the measures used in G1 and G2.

The treatment consisted of fractional radiofrequency application with in the areas to be treated, 8-needle and 25needle tips, which are disposable electrodes coupled to the accessories included in the equipment.

The procedure was performed with the volunteers on a stretcher, in dorsal decubitus, with no anaesthesia. The areas the applicators would penetrate were previously cleaned with $70 \%$-alcohol. The application was performed by a physiotherapist with the applicator positioned horizontally and during 10 minutes along the eye circumference, with superimposed passing, reaching the epidermal layer of the skin (Fig. 3).

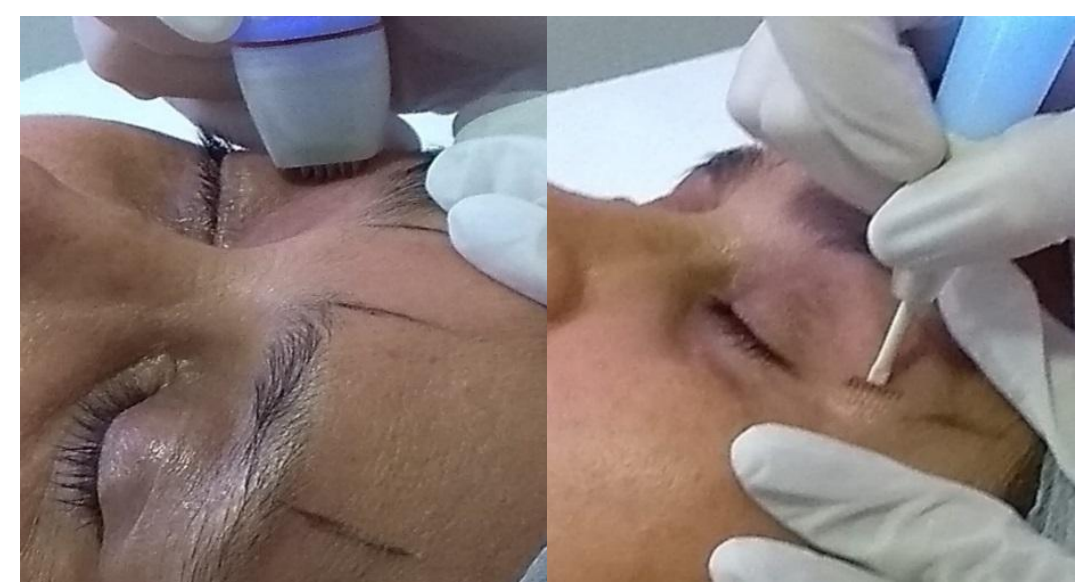

Figure 3. Presentation of the application of the electrodes on the skin. 
After the end of treatment, the photographic recording and measuring were repeated.

The result analysis occurred under the following criteria: the lower the post-evaluation results, the worse the eyelid flaccidity was considered due to ptosis, and the longer the measurement values, the more evident the improvement.

The parameters used in the Fractional Radiofrequency equipment were the same for both groups, and the only difference between them was the type of tip used during the sessions. The other settings were the same for both groups: amplitude: 100\%; time on: 50-ms deep; off-time: $5 \mathrm{~ms}$; pulse: 1; mode: pressed; $20 \mathrm{~mJ}$ of energy.

The photos obtained in the evaluations were sent to 17 professional physiotherapists, and each photo contained the following question: "Do you see improvements in the treated area?" "Yes/No". This photogrammetry, suggested by Mendonça et al. (2009), serves to analyse any signs of clinical improvement in the treated region from pre- and post treatment photos.

\section{Histological Analysis}

Only one of the volunteers underwent blepharoplasty (Fig. 4), during which two samples were taken from the skin flap of the upper palpebral region (Fig. 5).

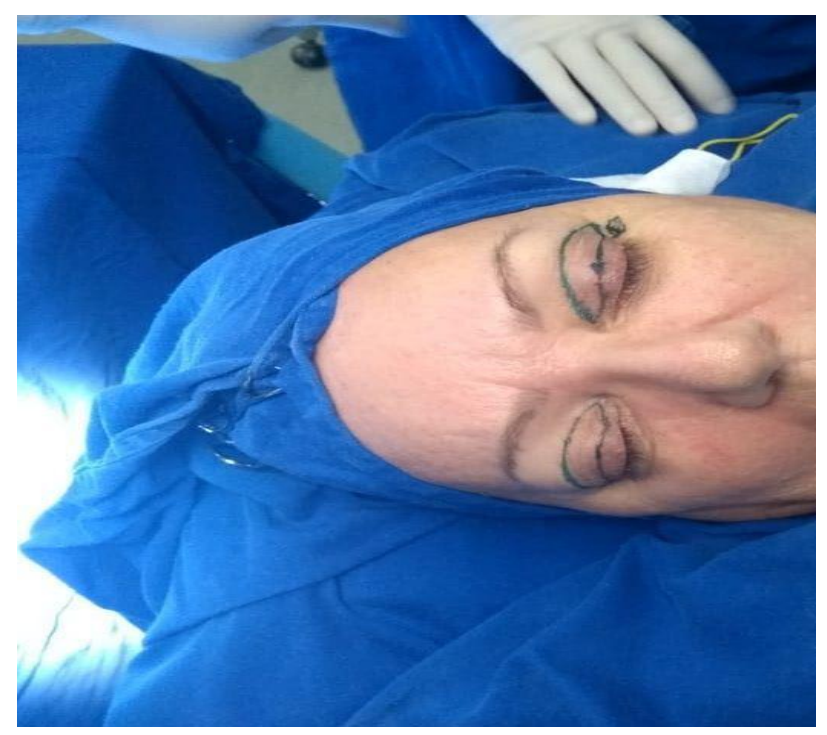

Figure 4. Blepharoplasty Surgery. 

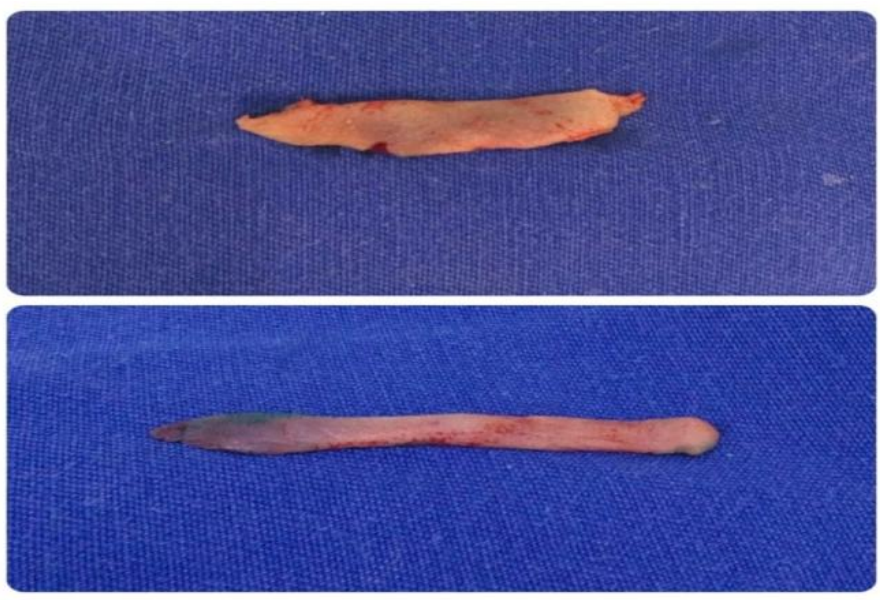

Figure 5. Skin flap samples.

After treatment conclusion, 15 days after the last session, only one volunteer from G1 received unilateral fractioned radiofrequency applications, that is, only the left eyelid was treated, with which the 25 -needle tip applicator was used.

The surgical procedure called blepharoplasty consists of correcting the changes caused by aging by removing excess skin and reducing fat pockets. The volunteer was sedated with local anaesthesia with $2 \%$-lidocaine with adrenaline at 1:200.000. An incision was made at the upper palpebral margin for the removal of the cutaneous flap and of adipose tissue, then sutured with absorbable blepharoplasty suture yarn (Vicryl 3-0).

\section{Data Analysis}

The clinical results were evaluated 15 days after treatment conclusion by means of photographic records and questionnaires. The Package Social Science software (SPSS version 22.0) was used for eyelid/eyebrow measurements analysis, which was performed and presented as mean and standard deviations, in graphs and tables. For inferential analysis, the Kolmogorov-Smirnov test was applied. For the intragroup comparison, the paired t-test and in the intragroup analysis were carried out. In all analyses, with $p<0.05$ level of significance. Regarding the blepharoplasty results, the qualitative analysis assessed via optical microscopy. The flap removed in the blepharoplasty surgery was wrapped in paraffin for slide preparation. Haematoxylin and eosin (HE) staining 40x, 100x, 400x were used to verify dermal, epidermal, and hypodermic tissues morphology. The criteria were the presence of edema, acute, and chronic inflammatory processes; the presence of fibroblasts, neo-collagen, and mature collagen.

\section{Results:-}

\section{Clinical Analysis}

The treatment was initiated with G1 (25 needle-tip) and G2 (8 needle-tip), totalling 10 volunteers from 47 to 62 years old, with a mean age of $53.5 \pm 4.95$ years, with no patient withdrawals..

\section{Measurement Analysis}

Table 1 shows the eyelid/eyebrow distance measurement results, and the following changes were observed:

Table 1:-Results eyelid/eyebrow measurement

\begin{tabular}{|c|c|c|c|}
\hline & Before & After & P value \\
\hline Distance from the eyes & $2.31 \pm 0.38$ & $2.25 \pm 0.39$ & 0.52 \\
\hline Length of eyebrow & $5.49 \pm 0.47$ & $5.5 \pm 0.37$ & 0.88 \\
\hline Highest point & $2.78 \pm 0.28$ & $2.96 \pm 0.18$ & $0.03^{*}$ \\
\hline
\end{tabular}




\begin{tabular}{|c|c|c|c|}
\hline $\begin{array}{c}\text { Right eye } \\
\text { Initial height }\end{array}$ & $1.31 \pm 0.23$ & $1.46 \pm 0.18$ & $0.01^{*}$ \\
\hline Highest point height b & $1.43 \pm 0.41$ & $1.50 \pm 0.35$ & 0.19 \\
\hline Height endpoint c & $1.35 \pm 0.30$ & $1.52 \pm 0.19$ & 0.09 \\
\hline $\begin{array}{c}\text { Left eye } \\
\text { Initial height }\end{array}$ & $1.51 \pm 0.64$ & $1.53 \pm 0.18$ & 0.92 \\
\hline Highest point height b & $1.53 \pm 0.31$ & $1.55 \pm 0.33$ & 0.67 \\
\hline Height endpoint c & $1.42 \pm 0.33$ & $1.56 \pm 0.26$ & 0.17 \\
\hline
\end{tabular}

Only the first measurement evidenced a decrease in value after treatment, which means that treatment did not indicated skin improvement. The other values presented increase after treatment, which corresponds to a probable flaccidity decrease (Fig. 6 and 7).

Figure 6. Result of variable highest point A

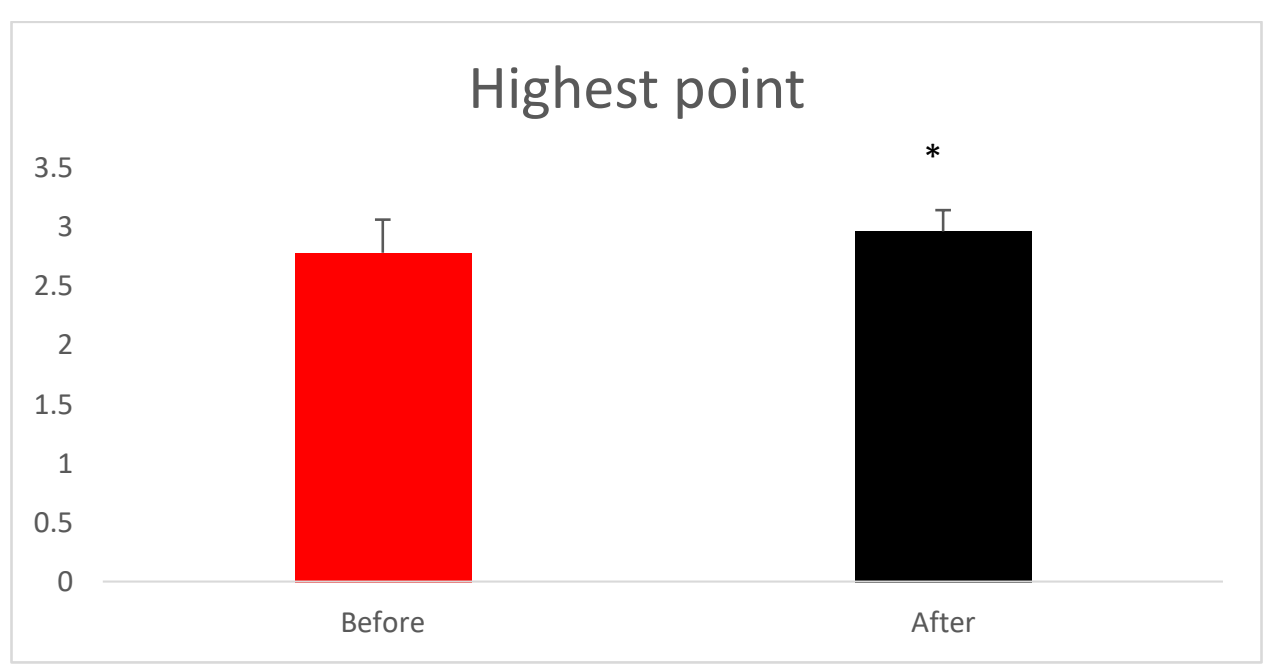

Figure 7. Result of variable highest point A

\section{Right eye height}

$$
\begin{array}{r}
1.8 \\
1.6 \\
1.4 \\
1.2 \\
1 \\
0.8 \\
0.6 \\
0.4 \\
0.2 \\
0
\end{array}
$$

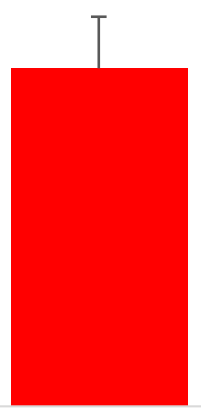

Before

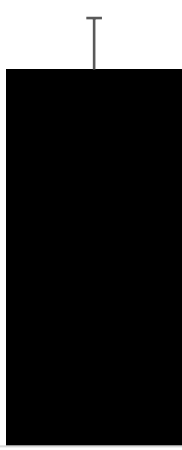

After 


\section{Photographic Analysis}

Photos were taken in all sessions and also 15 days after the last treatment session. The results were assessed through photogrammetry, which allowed flaccidity improvement verification of the treated region (Fig. 8).

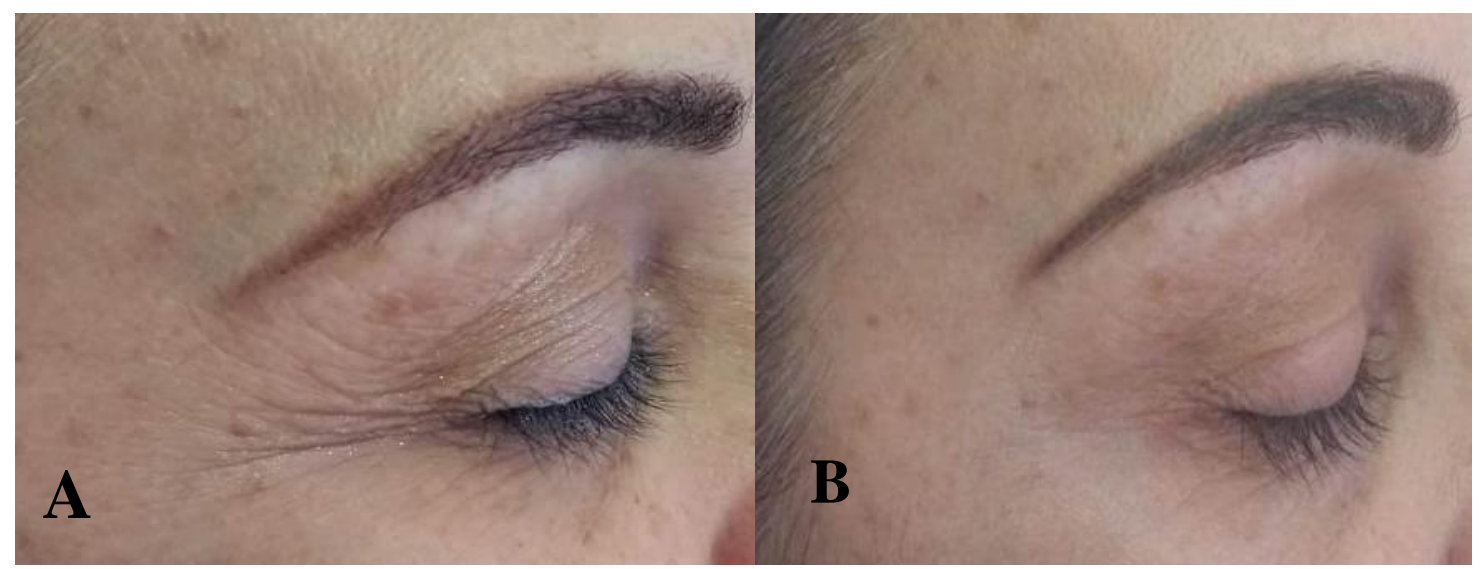

Figures 8. Photographic sample of the evaluations corresponds to (A) photograph of the lateral region of the first evaluation before treatment (B) photograph of the lateral region after 15 days after treatment.

Table 2 shows the distribution of absolute frequencies regarding improvement perception after fractional radiofrequency treatment based on the opinion of the professionals who evaluated the study.

Table 2:-Absolute frequency distribution regarding improvement perception after the interventions according to the photogrammetry.

\begin{tabular}{|c|c|c|}
\hline Improvement of the previous view & Absolute Frequency & Relative Frequency \\
\hline No & 46 & 31.3 \\
\hline Yes & 101 & 68.7 \\
\hline Total & 147 & 100.0 \\
\hline Improvement of the lateral view & & 7 \\
\hline Did not answer & 1 & 31.3 \\
\hline No & 100 & 68.0 \\
\hline Yes & 147 & 100.0 \\
\hline Total & & \\
\hline
\end{tabular}

In the photogrammetry, it was possible to observe that in the previous view, 101 responses stated that there was improvement after treatment, and 46 non-improvement responses in absolute numbers. And from the side view, the absolute frequency of 100 responses evidenced that there was improvement after treatment and absolute frequency of 46 responses of non-significant improvement, and only 1 volunteer did not respond the questionnaires. Regarding the treated and analysed sample, 7 volunteers reported higher numbers of "YES" responses for treatment improvement and 3 volunteers had greater numbers of "NO" responses.

\section{Analysis Of Questionnaires}


At the end of all 4 sessions, the volunteers were asked to answer a compilation of the Narins' Global Aesthetic Improvement Scale (GAIS) and the Segot-Chicq adapted satisfaction questionnaires, which consisted of 10 questions regarding the treatment and the perceived effects on the skin for each question. Tables 3,4 , and 5 represent the questions and their respective results.

Table 3:-Distribution of absolute and relative frequencies of questionnaires on the satisfaction of volunteers.

\begin{tabular}{|c|c|c|}
\hline & Absolute Frequency & Relative Frequency \\
\hline REDNESS & 4 & 25.0 \\
\hline $\begin{array}{c}\text { In the first } \\
\text { two sessions }\end{array}$ & 2 & 12.5 \\
\hline $\begin{array}{c}\text { In the first } \\
\text { four sessions }\end{array}$ & 10 & 62.5 \\
\hline In all sessions & & \\
\hline REDNESS LASTING PERIOD & 7 & 43.8 \\
\hline one hour & 5 & 31.3 \\
\hline 2 to 3 hours & 4 & 25.0 \\
\hline more than 3 hours & & \\
\hline $\begin{array}{c}\text { LOW SHOCK DURING } \\
\text { APPLICATIONS }\end{array}$ & 1 & 6.3 \\
\hline No & 1 & 6.3 \\
\hline Yes & 1 & 6.3 \\
\hline $\begin{array}{c}\text { In the first } \\
\text { two sessions }\end{array}$ & 13 & 81.3 \\
\hline In all sessions & & \\
\hline
\end{tabular}

Table 4:-Distribution of absolute and relative frequencies of questionnaires regarding the volunteers' satisfaction.

\begin{tabular}{|c|c|c|}
\hline MARKS ON THE SKIN & 3 & 18.8 \\
\hline No & 1 & 6.3 \\
\hline Yes & 3 & 18.8 \\
\hline $\begin{array}{c}\text { In the first } \\
\text { two sessions }\end{array}$ & 1 & 6.3 \\
\hline $\begin{array}{c}\text { In the first } \\
\text { four sessions }\end{array}$ & 8 & 50.0 \\
\hline In all sessions & 1 & 6.3 \\
\hline How long did it last? & 1 & 6.3 \\
\hline No & 3 & 18.8 \\
\hline Yes & 10 & 62.5 \\
\hline $\begin{array}{c}\text { For first } \\
\text { two sessions }\end{array}$ & & \\
\hline For four sessions & & \\
\hline
\end{tabular}

Table 5Distribution of absolute and relative frequencies of questionnaires on the satisfaction of volunteers.

\begin{tabular}{|c|c|c|}
\hline SKIN TEXTURE & 5 & 31.3 \\
\hline With much more firmness & 7 & 43.8 \\
\hline With more firmness & 2 & 12.5 \\
\hline With firmness & 1 & 6.3 \\
\hline I did not see any difference & 1 & 6.3 \\
\hline Did not answer & & \\
\hline SATISFACTION WITH THE & 14 & 87.5 \\
\hline RESULTS & 2 & 12.5 \\
\hline Yes & 16 & 100.0 \\
\hline No & & \\
\hline Total & & \\
\hline
\end{tabular}




\begin{tabular}{|c|c|c|}
\hline TREATMENT EVALUATION & & 56.3 \\
\hline Excellent treatment & 9 & 12.5 \\
\hline Very good treatment & 2 & 25.0 \\
\hline Good treatment & 4 & 6.3 \\
\hline Weak treatment & 1 & 6.3 \\
\hline $\begin{array}{c}\text { GLOBAL AESTHETIC } \\
\text { IMPROVEMENT SCALE }\end{array}$ & 1 & 37.5 \\
\hline Unchanged & 6 & 31.3 \\
\hline Best & 5 & 25.0 \\
\hline Much better & 4 & \\
\hline
\end{tabular}

It was possible to observe that regarding redness, $62.5 \%$ of the volunteers presented this reaction, which lasted about one hour among $43.8 \%$ the patients. The sensation of slight shocks was reported by $81.3 \%$, and $50 \%$ showed temporary marks on the skin after the session. The marks disappeared after 15 days. Regarding skin texture, $43.8 \%$ observed more firmness. In the satisfaction results analysis, $87.5 \%$ reported being satisfied with the results and $56.3 \%$ considered the results excellent. The percentage of positive responses regarding the overall aesthetic improvement was $93.7 \%$, which demonstrates an important degree of satisfaction with the overall facial appearance.

\section{Quantitative Analysis Of Histological Material}

A quantitative analysis of the histological material of the fragment removed in blepharoplasty was carried out using HE staining and with the assistance of 100x magnification under light microscopy (Fig. 9). 
Figure 9. Histological sample of cutaneous flaps: (A) to side control; (B) treated side.

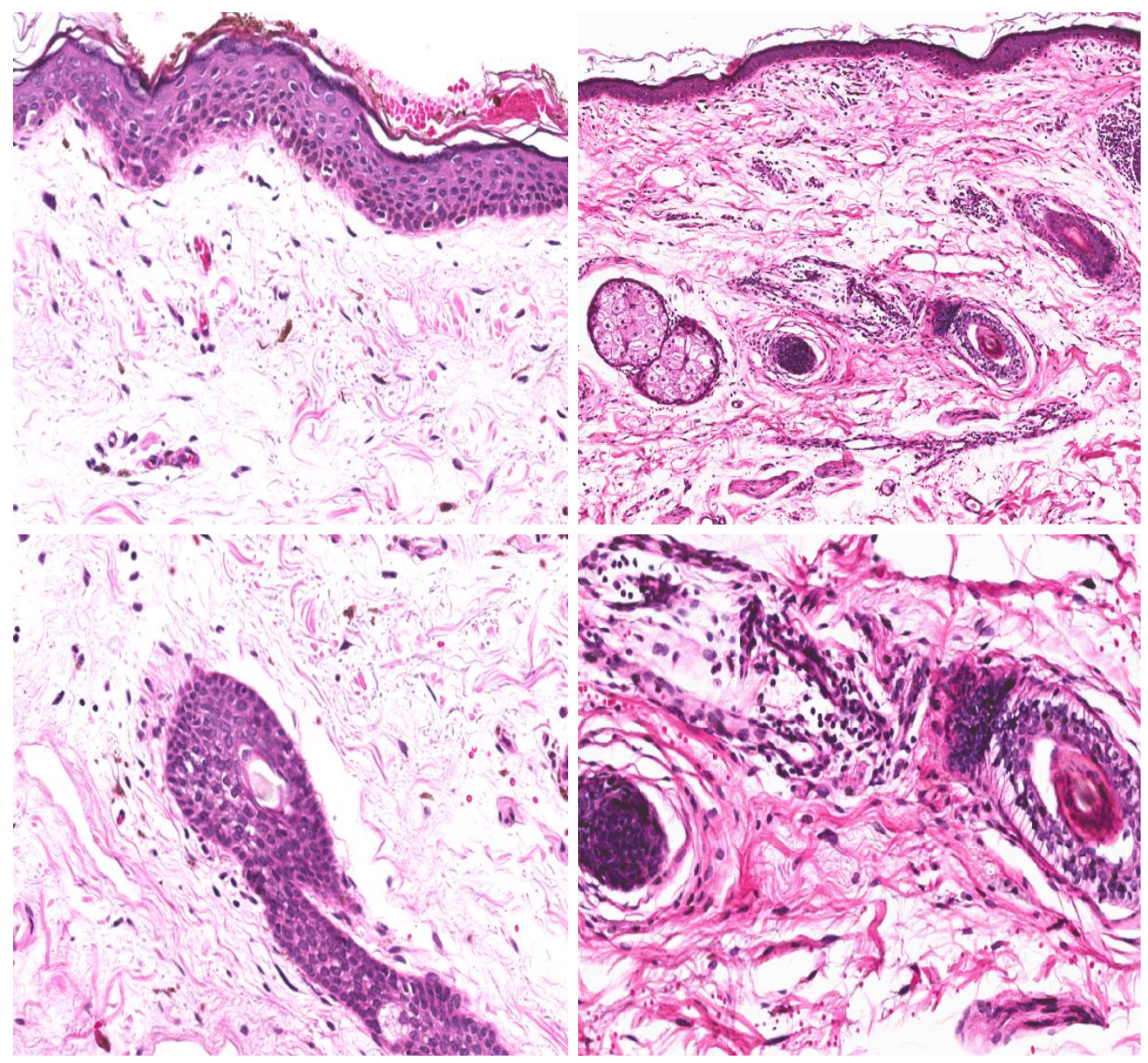

A

Figure A shows the control side, in which the skin in the dermal region presents normal accumulation of liquid in the tissues. Also, there are a few well-dispersed inflammatory cells and fibroblasts components(collagen and elastin). In figure B, which represents the treated side, it is possible to observe the oedematous skin, a chronic perivascular and perianexial inflammation and, compared to control, where there were many dispersed fibroblasts, it now presents more collagen fibre deposition, which promotes tonicity improvement and sagging reduction.

\section{Discussion:-}

The volunteers presented a high mean age value; consequently, the eyelid flaccidity was evident within the individuals in the sample. From the age of 40, the decrease in collagen fibres begins to occur, resulting in the reduction of both skin elasticity and firmness (Huang et al., 2018). 
Regarding results of eyelid/eyebrow measurements, it was noticed that there was an increase in this measurement value. This result may signal sagging decrease, as during the treatment collagen and elastin deposition occurs in the treated region, causing the skin to stretch. The mechanisms of action of radiofrequency include the uniform heating of the dermal layers in a deep and controlled fashion, resulting in immediate collagen shrinkage and its subsequent remodelling. If this alteration occurs in the eyelid region, the distance between the eyebrow and the eyelid increases, giving a smaller aperture image of the eye. A similar result is obtained with the blepharoplasty. In addition, photographic registration and measurement of eyelid distances are procedures that allow quantitative assessments and reinforce the results of some treatment techniques, whether conservative or not (Domyati et al., 2011; Silva and Tokars, 2013).

In the photographic analysis, the photos showed positive results after treatment with the aid of photogrammetry. According to the evaluators' analyses, satisfactory results were obtained for both the anterior and the lateral regions, and sagging decrease was observed in the treated region, despite all the difficulties faced with photographic analyses.

In this perspective, when compared to another study in which only a single session of ablative radiofrequency application was performed with $345 \mathrm{~mJ}$ energy, it was possible to observe the same skin contraction effect on the eyelids, with similar skin texture improvement (Casabona et al., 2014). Considering that this research used lower doses $(20 \mathrm{~mJ})$, without the need for anaesthesia, the results favour the semiablative radiofrequency as it is more comfortable for the patient, with lower risk and similar aesthetic effects if applied in high doses.

Regarding skin reactions during sessions, the volunteers reported redness, a reaction considered normal in literature. When the dermis and the hypodermis are heated, one of the consequences is the hyperaemia, which is the result from vasodilation, and the thermal effect that will promote collagen fibres contraction and stimulate their production (Nery, 2016).

Regarding the shock sensation, the volunteers reported having felt it during the applications, which corroborates with the reported in the study of Low and Reed (2001), in which they affirm that the equipment tip rubbing causes temperature increase, as it transforms the electricity into heat. This explains why volunteers feel slight shocks during the application, also bearing in mind that the eyelid region presents greater sensitivity. Another possible explanation for the "sensation of shock" could be the possible stimulation of muscular fibres or nerves by the tip, which could cause higher local excitability (Low and Reed, 2001).

In this type of configuration, heat zones, selectively heated, are created on the surface of the skin, generating crusts and temporary marks that usually disappear after 15 to 30 days. In this study, marks on the eyelid region remained visible for up to 15 days in $6.3 \%$ of the volunteers, who probably had thinner and more sensitive skin, corroborating the results from the study of Hruza et al. (2009).

Regarding the post treatment skin look and feel, the validated satisfaction assessment presented satisfactory results. The volunteers reported mostly firmer skin and better texture when compared to pre-treatment skin. The study demonstrated that the fractional radiofrequency (semiablative) had its effectiveness in decreasing skin flaccidity, fine lines and wrinkles, and in improving texture, corroborating with the results obtained by Blomm et al., (2012). Previous studies have shown that ablative fractional radiofrequency devices improve skin overall conditions, that is, its shine, flaccidity level, and wrinkling, with minimal side effects (Armenakas et al., 2010; Man et al., 2012).

Regarding the Global Aesthetic Improvement Scale (GAIS) questionnaire, which was used in the obtention of answers regarding the treatment, the volunteers rated their improvement from "better" to "much better/best", which means that treatment with fractional radiofrequency was successful for eyelid flaccidity. According to the study carried out by Sun et al. (2018), twenty healthy Chinese volunteers with facial skin were selected, each receiving three sessions of fractional radiofrequency treatment with 4-week intervals between sessions. Changes in photoaging were analysed by an overall assessment, a subjective assessment, a Mexameter, and the VISIA SCAN software. The evaluator classified the volunteers as "good" or "excellent", and thirteen out of eighteen volunteers, which corresponded to $72.2 \%$, evaluated their overall impression as "satisfied" or "very satisfied" (Sun et al., 2018). 
The results obtained by Samadi et al. (2018) also corroborates with the ones in this study. Fifteen female volunteers with mean age of 47.7 years were divided into two groups, in which the first received three fractional radiofrequency applications, and the other received six conventional bipolar radiofrequency applications in three weeks. In their clinical evaluation, significant improvement in the Glogau wrinkle score was shown after three months with both treatments. The area and volume of nasolabial folds were also significantly reduced, and skin ultrasonography showed significant improvement, which was confirmed by the histological findings of increased dermal collagen content with the fractional radiofrequency treatment procedure (Samadi et al., 2018).

In this research, the histological analysis showed that when compared to untreated (control) skin analysis, the obtained results confirm significant improvement in all regions, showing a higher presence of collagen and inflammatory cells, confirming that fractional radiofrequency treatment for skin flaccidity has its effectiveness at histological level. According to a study by Casabona et al. (2014), with similar methodology, the procedure managed to reach the papillary dermis 100-microns deep, causing ablation and coagulation of surrounding proteins through residual thermal damage and positive results regarding the presence of collagen in the palpebral tissue.

However, the fact that only one out of all volunteers was submitted to blepharoplasty for posterior histological analysis was also considered a limitation, thus hindering the presence of more significant results. Therefore, it is suggested that further studies are performed to prove and validate the efficacy of semiablative fractional radiofrequency eyelid flaccidity in order to obtain additional corroborating results.

\section{Conclusion:-}

The semiablative fractional radiofrequency was safe for the patients and demonstrated results for the treatment of palpebral flaccidity of all volunteers. In the clinical analysis, considerable aesthetic improvement of the treated region was observed through greater firmness and better skin texture. In the histological analysis, the greater number of inflammatory cells and an increase in the amount of newly formed collagenous tissue on the treated side was evident. From the analysis of the questionnaires and photos, the volunteers and photogrammetry examiners positively evaluated the treatment, demonstrating, despite the limitations of this study, that semiablative fractional radiofrequency is an indicated and effective treatment for eyelid flaccidity.

\section{References:-}

1. Akita H, Sasaki R, Yokoyama Y, Negishi K, Matsunaga K (2014). The clinical experience and efficacy of bipolar radiofrequency with fractional photothermolysis for aged Asian skin. Exp Dermatol., 4(23):37-42.

2. Alexiades M., Munavalli G., Goldberg D., Nerube D. (2018): Prospective Multicenter Clinical Trial of a temperature-controlled subcutaneous microneedle fractional bipolar radiofrequency system for the treatment of cellulite. Dermatology Surgery., 44(10): 1262-1271.

3. Armenakas M., Rosenberg D., Renton B., Dover J., Arndt K. (2010): Blinded, randomized, quantitative grading comparison of minimally invasive, fractional radiofrequency and surgical face-lift to treat skin laxity. Arch Dermatol., 146: 396 - 405.

4. Bloom, B.S., Jason E., David J., Goldberg. (2012): Assessment of safety and efficacy of a bipolar fractionated radiofrequency device in the treatment of photodamaged skin. Journal of Cosmetic and Laser Therapy., 14: 208-211.

5. Carvalho G.F., Da Silva R.M.V., Mesquita Filho J.J.T., Meyer P.F., Ronzio O.A., Medeiros J.O., Nóbrega M.M. (2011): Avaliação dos efeitos da radiofrequência no tecido conjuntivo. Especial Dermatologia., 65: 1025 .

6. Casabona G., Presti C., Manzini M., Machado Filho C.D.S. (2014): Fractional ablative radiofrequency: a pilot study of twenty cases involving rejuvenation of the lower eyelid, Surg Cosmet Dermatol., 6(1): 50-55.

7. Chrastil B, Glaich AS, Goldberg LH, Friedman PM. (2008): Secondgeneration 1,550-nm fractional photothermolysis for the treatment of acne scars. Dermatol Surg., 34: 1327-1332.

8. Domyati M., El-Ammawi T.S., Medhat W. et al. (2011): Radiofrequency facial rejuvenation: evidence-based effect. J Am Acad Dermatol., 64: 524-535.

9. Fitzpatrick R, Geronemus R, Goldberg D, Kaminer M, Kilmer S, Ruiz-Esparza J. (2003): Multicenter study of noninvasive radiofrequency for periorbital tissue tightening. Lasers Surg Med., 33:232-242.

10. Hruza, A.F., Taub, S.L., Collier S., Mulholland R. (2009): Skin rejuvenation and wrinkle reduction using a fractional radiofrequency system. Journal of Drugs in Dermatology., 8(3): 259-265. 
11. Huang J., Wenyou Y., Zhang Z., Xiangdong C., Ewelina B. (2018): Clinical and Histological Studies of Suborbital Wrinkles Treated with Fractional Bipolar Radiofrequency. Rejuvenation research., 21(2). DOI: 10.1089/rej.2017.1947

12. Kołodziejczak A.M., Rotsztejn H. (2017): Mexametric and cutometric assessment of the signs of aging of the skin area around the eyes after the use of non-ablative fractional laser, non-ablative radiofrequency and intense pulsed light. Dermatology Therapy., 30(2).

13. Low J., Reed A. (2001): Eletroterapia explicada: princípios e práticas. São Paulo: Manole. 3 ed.

14. Man J., Goldberg D.J. (2012): Safety and efficacy of fractional bipolar radiofrequency treatment in Fitzpatrick skin types V-VI. J Cosmet Laser Ther., 14: 179-183.

15. Mendonça, A.M.S. et al. (2009): Confiabilidade e interexaminadores da fotogrametria na classificação do grau de lipodistrofiaginóide em mulheres assintomáticas. Fisioterapia e Pesquisa., 16(2): 102-106.

16. Nery, A.L.M. et al. (2016): Avaliação da eficácia do aparelho de radiofrequência para amenização de flacidez facial decorrente do envelhecimento cutâneo. Revista Iniciação Científica., 90-96.

17. Samadi A., Nasrollahi S.A., Janani L., Moosavi Z.B., Hesari K.K., Kalantari A.R., Firooz A. (2018): Combination of fractional radiofrequency and thermo-contraction systems for facial skin rejuvenation: a clinical and histological study. Aesthet Surg J., 12(38): 12.

18. Segot-Chicq, E. et al. (2007): Development and validation of a questionnaire to evaluate how a cosmetic product for oily skin is able to improve well-being in women. Journal of the European Academy of Dermatology and Venereology., 21(9): 1181-1186.

19. Silva, P.M., Tokars, E. (2013): Estimulação da neocolanogênese através da radiofrequência, Revista eletrônica saúde e ciência., 3(2): 1-9.

20. Sun Y., Luo Y.J., Li $\quad$ Z., Yu A.J., Gong $\quad$ L., Li $\quad$ Y.H. $\quad$ (2018): Application of a new fractional radiofrequency device in the treatment of photoaging skin in Chinese patients. J Cosmet Laser Ther., 12: 1-6.

21. Tierney, E.P. et al. (2012): Ablative fractionated CO2 laser treatment of photoaging: a clinical and histologic study. Dermatologic Surgery., 38(11): 1777-1789.

22. Vejjabhinanta V, Wanitphakdeedecha R, Limtanyakul P, Manuskiatti W (2014): The efficacy in treatment of facial atrophic acne scars in Asians with a fractional radiofrequency microneedle system. J Eur Acad Dermatol Venereol., 28:1219-1225. 